\title{
The use and effects of synthetic cannabinoid receptor agonists by New South Wales cannabis treatment clients
}

\author{
Melissa A. Jackson ${ }^{1 *}$, Amanda L. Brown ${ }^{1}$, Jennifer Johnston², Richard Clancy ${ }^{3}$, lain McGregor ${ }^{4}$, \\ Raimondo Bruno ${ }^{5}$, Nick Lintzeris ${ }^{6}$, Mark Montebello $^{7}$, Jennifer Luksza ${ }^{8}$, Jenny Bowman ${ }^{9}$, Nghi Phung ${ }^{10 \wedge}$, \\ Dave Allsop ${ }^{4 \wedge}$ and Adrian J. Dunlop ${ }^{1}$
}

\begin{abstract}
Introduction: Despite decreasing consumption by general populations, use of synthetic cannabinoid receptor agonists (SCRAs) persists in some marginalised groups, including those who use other substances. This article explores SCRA consumption in an Australian cannabis treatment sample, comparing those who report ever using SCRAs with those who have never used SCRAs.

Methods: A questionnaire orally administered in person to a convenience sample of 154 cannabis treatment service clients from New South Wales, Australia (71\% male, median age 35) collected information regarding cannabis and SCRA use including motivations, effects and health-related consequences of use, demographics, other substance use and overall health. Demographic profiles and between-group differences were explored. McNemar tests compared effects of SCRA and cannabis. Logistic regression analysis determined predictors of SCRA use.

Results: Half (53\%) reported lifetime SCRA use; 20\% reported previous-month use. The SCRA + cannabis group displayed greater polysubstance use and psychological distress. Reduced dependence on cannabis but higher levels of other substance use may predict SCRA use. Although curiosity motivated initial SCRA consumption, perceived psychoactive strength drove continued use. SCRAs appear to induce more negative side-effects than cannabis. Of the SCRA + cannabis group, 27\% sought medical assistance for SCRA use. Most (90\%) preferred cannabis to SCRAs, citing superior safety, effects and consistency of cannabis.

Conclusions: Among clients seeking treatment for cannabis use, SCRA use was relatively common, although not a preferred substance. Hazardous substance use and poor mental health characterised SCRA consumers, highlighting the need for continued monitoring by researchers and treatment providers of SCRA consumption in populations who use substances.
\end{abstract}

Keywords: Synthetic cannabinoid receptor agonist, Synthetic cannabinoids, Cannabis, Marijuana, Substance use disorder, Treatment

*Correspondence: Mel.Jackson@health.nsw.gov.au

1 Drug and Alcohol Clinical Services, Hunter New England Local Health District, Level 3, 670 Hunter Street, Newcastle, NSW 2290, Australia

Full list of author information is available at the end of the article

\section{Background}

The past decade has seen the emergence of a novel class of drugs known collectively as New Psychoactive Substances (NPS). These have proliferated across global drug markets, posing considerable challenges to public health, law enforcement and drug policy (European Monitoring 
Centre for Drugs and Drug Addiction and Europol 2019). Synthetic cannabinoid receptor agonists (SCRAs) are currently the largest substance sub-category within the class, encompassing at least 180 distinct molecular entities (Potts et al. 2020). These laboratory-made chemical compounds were first introduced into the Western European recreational drug markets in 2004 after being found to mimic some effects of cannabis intoxication. Manufactured in powder form, SCRAs are typically mixed with organic plant material to create herbal smoking products that resemble cannabis itself. However, an increase in seizures of powder, tablet and liquid forms has been observed in recent years (European Monitoring Centre for Drugs and Drug Addiction 2017). Although they share some psychoactive similarities, SCRAs are structurally distinct from plant-based delta 9 tetrahydrocannabinol $(\triangle 9-\mathrm{THC})$, a partial agonist of human CB1 and CB2 receptors. SCRA's are generally full CB1 agonists (Seely et al. 2012), typically creating outcomes more rapid and intense than those experienced with cannabis (Fantegrossi et al. 2014). Cannabis also contains cannabidiol, a phytocannabinoid thought to be responsible for counteracting some of the harmful psychoactive effects of $\Delta$ 9-THC (Swift et al. 2013). It is believed that similar protective agents lacking in SCRA's potentially compound their harmful outcomes, particularly increasing the risk of psychosis in users (Spaderna et al. 2013; van Amsterdam et al. 2015).

SCRAs emerged as a drug of concern in the USA, Australia and New Zealand around 2010-2011 (Barratt et al. 2013). In Australia, attempts by state and federal regulators between 2012 and 2015 to schedule individual SCRA compounds did little to halt the chemical diversity and increasing number of new variants entering the market (Cairns et al. 2017). Federal drug analogue legislation was introduced in 2015 prohibiting all substances with chemical structures or psychoactive effects similar to those of previously controlled psychoactive drugs (excluding alcohol, tobacco and food products). Several Australian states (New South Wales, Queensland, South Australia and Victoria) adopted blanket bans to prohibit SCRA use, possession, production and supply, while other states and territories continue to schedule individual NPS as they emerge (Grigg et al. 2020).

Similar drug laws have been introduced internationally to regulate SCRAs and NPS more broadly. In the USA, Federal laws have placed SCRAs in Schedule I of the Controlled Substances Act, with individual states banning some or all SCRA compounds (Cairns et al. 2017). In Canada, all substances that mimic cannabis are listed as a Schedule II drug under the Controlled Drugs and Substances Act S.C. 1996, c. 19. (Canada). Such laws have been effective in reducing their availability and use (European Monitoring Centre for Drugs and Drug Addiction 2018), while increases in harmful SCRA use in regions where individual scheduling continues (Grigg et al. 2020). The European Monitoring Centre for Drugs and Drug Addiction Early Warning System identified 215 novel NPS between 2015 and 2017, noting the first decrease in new SCRA identifications in 2017 (European Monitoring Centre for Drugs and Drug Addiction 2018). Despite this, SCRAs remain the most frequently seized NPS worldwide and their use in parallel with other substances, particularly by high-risk populations, remains evident (Blackman and Bradley 2017; Joseph et al. 2019).

\section{Who uses SCRAs?}

Early SCRA demographic profiling suggested consumers were young, well-educated males with high rates of employment, who also used cannabis, alcohol and tobacco (Barratt et al. 2013; Winstock and Barratt 2013b; Vandrey et al. 2012). Changing legislation and increased awareness of SCRA harms has seen large declines in consumption. SCRA use is now more commonly reported in people involved in the criminal justice system who may be seeking to avoid drug detection (Smith et al. 2017) and in other groups exposed to risk including homeless people, those with a history of mental illness and other psychoactive substance consumers (Clancy et al. 2018; Joseph et al. 2019; Ralphs et al. 2017; Sutherland et al. 2016; Peacock et al. 2019). A 2016-2017 US sample from a community-based support organisation for people who use drugs described recent SCRA consumers as older males, commonly diagnosed with psychiatric illness, who report concomitant use of SCRA with other substances, particularly opiates (Joseph et al. 2019). In Australia, SCRA use is more commonly seen in people who use cannabis and/or methamphetamines, or who regularly use multiple substances, or who experience social disadvantage and report difficulties ceasing substance use (Sutherland et al. 2018; Manseau et al. 2017).

\section{Motivations to use SCRAs}

Studies exploring motivations to use SCRAs have cited explanations including the desire for novel euphoric experiences and an alternative to cannabis. Other drivers draw on the novel characteristics of SCRAs including their accessibility, intense recreational effects, value for money and ability to evade detection in drug screening (Barratt et al. 2013; Vandrey et al. 2012; Bonar et al. 2014; Macgregor and Payne 2013). Early reports of motives for initial SCRA consumption suggested curiosity, availability and legal access (Barratt et al. 2013; Vandrey et al. 2012). Motivations vary according to the population 
under study: individuals enrolled in US-based residential substance use treatment programmes who used SCRAs, cited peer influence and the desire to avoid positive drug screenings (Smith and Staton 2019). Reasons behind continued SCRA use, or about the internal drivers of SCRA use, are not well understood.

\section{Health-related consequences of SCRA use Physical and psychological effects}

Awareness of the acute and long-term physical and psychological harms of SCRAs has developed in recent years. Their ability to produce euphoric effects similar to those of cannabis, but with a wider range of negative consequences, has been described (Fattore and Fratta 2011; Spaderna et al. 2013; van Amsterdam et al. 2015). Tachycardia, anxiety, agitation, paranoia and nausea are the most common adverse effects of SCRA intoxication (Tait et al. 2016). Those not often seen with cannabis include seizures, agitation, hypertension and hypokalaemia (Fattore 2016). More severe complications include seizures, acute kidney injury, cardiac arrest, mood disturbances, acute psychosis and death (Darke et al. 2020). Direct comparisons of positive and negative effect domains have revealed more positive effects and ability to function during cannabis intoxication, while SCRA intoxication provides more negative effects and hangover symptoms (Winstock and Barratt 2013).

\section{Treatment utilisation}

A 2012 global anonymous, online assessment of drug use found past year SCRA consumers $(n=2176)$ to be 30 times more likely to require emergency medical treatment following use compared to individuals following cannabis use, demonstrating the elevated risk of shortterm harm carried by acute SCRA use (Winstock et al. 2015). Survey data from 2011 indicated that $2.4 \%$ of past year SCRA consumers $(n=980)$ sought emergency medical treatment, presenting primarily for panic, anxiety, paranoia and breathing difficulties (Winstock and Barratt 2013a). Information from Internet-based substance use samples, however, may not be broadly representative of people who use cannabis.

\section{Aims of the current study}

Despite an overall decrease in availability and use of SCRAs, consumption in marginalised groups, including individuals with a history of substance dependence or criminal justice system involvement and those who experience social disadvantage, is still a concern. The current study will add to the existing body of SCRA literature by providing the first exploration of SCRA consumption in an Australian cannabis treatment sample. Its aims are to:
1) Compare groups of people in treatment for cannabis use-those who report ever using SCRAs with those who have never used SCRAs-in terms of demographics, substance use and health

2) Examine the factors influencing decisions to use or not to use SCRAs

3) Explore the experiences and outcomes of SCRA use with those who report ever using them

\section{Methods \\ Procedure}

The study was coordinated by a drug and alcohol clinical research unit located within Hunter New England Local Health District and received ethical approval from South East Sydney Local Health District Human Research Ethics Committee (Ref no: 15/030 HREC/15/ $\mathrm{POWH} / 56$ ) and the University of Newcastle (Ref: H-2015-0120).

Potential participants were over 18 years of age and seeking assistance to manage their cannabis use from specialised cannabis treatment clinics in five local health districts across metropolitan, regional and rural NSW. They were asked by treating clinicians about their interest in participating in a study describing their experiences with cannabis and SCRAs if they had used them, or their reasons for not trying SCRAs if they had not used them. If they agreed, they were referred to a research staff member at each site and a face-to-face interview was arranged. Informed consent was obtained in writing from participants prior to interview commencement. No details were recorded about those who declined a referral for the research interview. All interviews were completed between July 2015 and April 2016.

Participants were grouped according to self-reported SCRA consumption: those who had never used SCRAs (cannabis-only group) and those who had used both cannabis and SCRAs (SCRA + cannabis group). Interview length varied; the SCRA + cannabis group took approximately $1 \mathrm{~h}$ and the cannabis-only group, approximately $30 \mathrm{~min}$. All participants were reimbursed with retail vouchers for the time associated with study participation: $\$ 40$ for the SCRA + cannabis group and $\$ 20$ for the cannabis only group.

\section{Measures}

Self-reported responses were collected from both groups to the following items (where indicated, the SCRA + cannabis group completed equivalent items relating to SCRA use). See Supplementary Materials for more detailed instrument descriptions and evidence of validity. 


\section{Demographic and substance use information}

Age, gender, aboriginal status, education, relationship status, living arrangements, income source, substance use history (lifetime, 3- and 1-month use, and days per month), detailed cannabis and SCRA use were recorded. Cannabis dependence was assessed using ICD-10 criteria with dependence considered if at least three of six criteria had been experienced concurrently in the previous 12-month period. (World Health Organization 1992).

\section{Effects of cannabis/SCRA use}

Thirty-five physiological, psychological and behavioural consequences of cannabis and SCRA use were rated by the extent to which respondents had experienced each of them while intoxicated $(1=$ never, $2=$ sometimes, $3=$ most of the time, $4=$ every time). Designed for the current study, the survey incorporated a range of effects (e.g. felt stimulated/energetic; increased ability to function; felt nervous or anxious).

\section{Drug Use Motive Questionnaire (DUMQ): cannabis/SCRAs} Adapted from the Drinking Motives Questionnaire (Cooper et al. 1992), this tool provides 17 reasons for using cannabis or SCRAs (responses: $1=$ never, $2=$ rarely, $3=$ sometimes, $4=$ often, $5=$ almost always) allowing selection of all applicable motivations and the most important overall. Responses are categorised into four motivational domains: social (e.g. to be sociable, to make social gatherings more enjoyable), coping (e.g. to forget worries, to increase confidence), pleasure enhancement (e.g. because it is fun, to get high) and illness (e.g. to reduce symptoms of mental illness). Higher scores indicate higher motivation.

\section{Mental health}

Psychological distress was measured using the 21-item Depression, Anxiety, Stress Scale (DASS21:Lovibond and Lovibond 1995). Three sub-scales assess associated symptoms during the previous week. Higher scores indicate higher distress.

\section{Health status}

General health status was assessed using the 36-item Short Form Health Survey version 2 (SF-36v2) (Ware et al. 2002). Health over a 4-week period is assessed across eight physical and mental health domains, providing two standardised global measures, the physical component and mental component summary. Higher scores suggest better quality of life.

Participants in the cannabis-only group completed:

\section{SCRA: no use}

Designed for the study, this questionnaire specifies 14 reasons for not trying SCRAs (e.g. not natural, no curiosity, heard bad/negative reports). Multiple responses are allowed, with the most important reason specified.

In addition to those previously indicated, participants in the SCRA + cannabis group completed:

\section{Comparing SCRAs and natural cannabis}

Participants indicated (a) which of the two drug-types was preferred overall and why and (b) which most met each of eight following criteria and why: consistency, value for money, self-rated addictive potential, positive effects when high, negative effects when high, harm to lungs, safety and long-lasting effects. Items were adapted from Winstock and Barratt (2013b).

\section{Reasons for first and subsequent SCRA use}

Thirteen identical reasons were offered for (a) initially trying and (b) continuing with SCRA use. Multiple responses were allowed and the most important reason for both identified. All items were adapted from Barratt et al. (2013).

\section{Utilisation of health services}

Participants are asked to specify any health-related treatment they received in relation to their SCRA use.

\section{Analysis}

Responses for all variables were analysed descriptively using bivariate associations and relative frequencies (with results stated as both a percentage and proportion of valid responses), means $(\mathrm{M})$ with standard deviation (SD) and where appropriate, medians (Mdn) with interquartile range (IQR). Student's $t$-test, Pearson's chi-square, Kruskal-Wallis and Mann-Whitney $U(\mathrm{U})$ tests were used to determine inter- and between-group differences with the magnitude of difference measured using Cohen's $d$. McNemar tests were used for within-subject proportional comparisons, with significant results provided using odds ratio (OR) and confidence intervals (CI). Logistic regression was used to determine participant characteristics that were associated with SCRA use while controlling for other variables. Predictor variables were those between group differences that were significant in bivariate analysis (at $p<0.05$ ).

Responses to the effects of SCRAs and cannabis items were categorised into 'effect absent' (never responses) and 'effect present' (sometimes, most of the time and always responses) to create paired $2 \times 2$ contingency tables. Conditional logistic regression established ORs 
Table 1 Sociodemographic characteristics of 154 participants undergoing treatment for cannabis use in New South Wales, Australia

\begin{tabular}{|c|c|c|c|c|}
\hline Demographic & $\begin{array}{l}\text { SCRA + cannabis }(n=82) \\
n(\%)\end{array}$ & $\begin{array}{l}\text { Cannabis-only }(n=72) \\
n(\%)\end{array}$ & $\begin{array}{l}\text { Total }(N=154) \\
n(\%)\end{array}$ & $p$-value \\
\hline Age in years $m d n(I Q R)$ & $32(11)$ & $37(10)$ & $35(10)$ & 0.17 \\
\hline \multicolumn{5}{|l|}{ Age range $n(\%)$} \\
\hline $18-35$ & $46(56 \%)$ & $34(47 \%)$ & $80(52 \%)$ & \\
\hline $36+$ & $36(44 \%)$ & $38(53 \%)$ & $74(48 \%)$ & 0.27 \\
\hline Male, $n(\%)$ & $62(76 \%)$ & $48(67 \%)$ & $110(71 \%)$ & 0.22 \\
\hline Aboriginal, $n(\%)$ & $8(10 \%)$ & $8(11 \%)$ & $16(11 \%)$ & 0.76 \\
\hline Education $\leq$ year 10, n (\%) & $45(55 \%)$ & $39(54 \%)$ & $84(55 \%)$ & 0.93 \\
\hline Single relationship status, $n$ (\%) & $53(65 \%)$ & $57(80 \%)$ & $110(72 \%)$ & 0.03 \\
\hline Live alone, $n(\%)$ & $19(23 \%)$ & $29(40 \%)$ & $48(31 \%)$ & 0.02 \\
\hline Government support, $n(\%)$ & $61(74 \%)$ & $52(72 \%)$ & $113(73 \%)$ & 0.76 \\
\hline
\end{tabular}

with CIs for each and McNemar tests verified significant differences.

\section{Results}

One hundred and fifty-four participants provided consent to participate and completed the interview process. Eighty-two were in the SCRA + cannabis group and 72 in the cannabis-only group. Frequencies differ in instances where participants did not provide responses.

\section{Demographic information}

Table 1 provides demographic information. A higher proportion of cannabis-only participants reported being single $(80 \%$ v $65 \%, p=0.03)$ and living alone $(40 \%$ v $23 \%$, $p=0.02)$.

\section{Substance use information}

Eighty-four percent (130/154) described use of cannabis in the previous month, consuming an average of 2.2 g/day on 19/28 days. Eighty-eight percent (135/154) met ICD-10 criteria for cannabis dependence. Average age of cannabis initiation was 14.4 $(\mathrm{SD}=3.0)$. Nearly all $(89 \%)$ used water pipes as their main route of administration but use of 'joints' (92\%; 142/154), dry pipe (82\%; $126 / 154)$, ingestion (77\%; 118/154) and vaping (29\%; 44/154) were also described.

Table 2 describes differences between groups in cannabis use characteristics. The cannabis-only group consumed significantly more cannabis $(2.8 \mathrm{~g}$ vs $1.7 \mathrm{~g}$, $p=0.03)$ more regularly $(21 / 28$ vs $16 / 28, p=0.01)$ and reported more symptoms of cannabis dependence $(\mathrm{Mdn}(\mathrm{IQR})=6(1)$ vs $5(2), p \leq 0.01)$ than those from the SCRA + cannabis group. The SCRA+cannabis group were more likely to have ingested cannabis orally $(71 / 82$ vs $46 / 72, p \leq 0.01)$ or smoked via a dry pipe $(73 / 82$ vs $53 / 72, p=0.02$ ) than the cannabis-only group.

Approximately half reported previous use of SCRAs (53\%; 82/154), with $20 \%$ reporting previous month consumption $(16 / 82)$ with the median being 20 days $(\mathrm{IQR}=27)$. Half $(50 \% ; 8 / 16)$ reported daily or almost daily use. Although half the sample had used SCRAs $\geq 20$

Table 2 Differences in cannabis use characteristics between the SCRA + cannabis group and the cannabis-only group participants

\begin{tabular}{|c|c|c|c|}
\hline Cannabis use characteristic & SCRA + cannabis $(n=82)$ & Cannabis-only $(n=72)$ & $p$-value \\
\hline Used in past 3 months, $n$ (\%) & $74(90 \%)$ & $68(94 \%)$ & 0.33 \\
\hline Used in past month, $n(\%)$ & $63(88 \%)$ & $67(91 \%)$ & 0.32 \\
\hline Number of days used in past month, $m(s d)$ & $16.4(11.2)$ & $21.0(10.3)$ & 0.01 \\
\hline Average amount used per day (grammes), $m(s d$ ) & $1.7(1.8)$ & $2.9(4.5)$ & 0.03 \\
\hline Age of initiation (years), $m(s d)$ & $14.2(3.0)$ & $14.7(2.9)$ & 0.33 \\
\hline No. of ICD-10 symptoms, mdn(IQR) & $5(2)$ & $6(1)$ & $<0.01$ \\
\hline \multicolumn{4}{|l|}{ Route of administration: } \\
\hline Water pipe, $n(\%)$ & $71(99 \%)$ & $82(100 \%)$ & 0.28 \\
\hline Joints, $n(\%)$ & 77 (94\%) & $65(90 \%)$ & 0.14 \\
\hline Dry pipe, $n(\%)$ & $73(89 \%)$ & $53(74 \%)$ & 0.02 \\
\hline Vaporiser, $n(\%)$ & $27(33 \%)$ & $17(24 \%)$ & 0.27 \\
\hline Ingested, $n$ (\%) & $72(88 \%)$ & $46(64 \%)$ & $<0.01$ \\
\hline
\end{tabular}




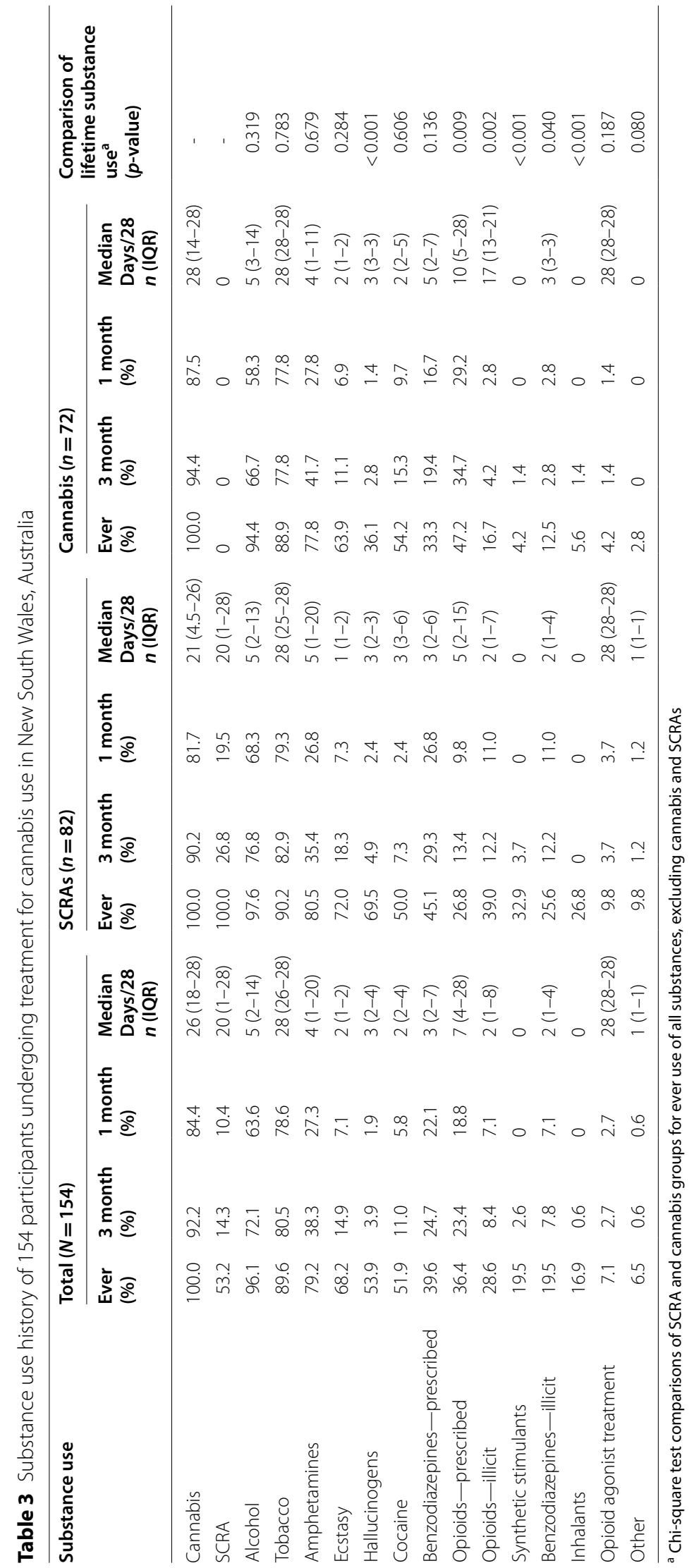


times (52\%; 43/82), one-third had attempted them less frequently (<5 times-37\%; 30/82). Many brands of SCRA were consumed with Kronic, Black Widow, K2 and Northern Lights the most commonly identified. The median age of first consumption was 29 years $(\mathrm{IQR}=19)$. Waterpipe was the main method of ingestion (95\%; $78 / 82)$ although smoking by joint $(27 \% ; 22 / 82)$ or dry pipe $(27 \% ; 22 / 82)$, as well as vaping $(2 \% ; 2 / 82)$ and injecting $(2 \% ; 2 / 82)$, was detailed. Mixing SCRAs with tobacco was also common (77\%; 63/82).

Self-reported substance use and between-group comparisons for a range of substances including SCRAs are described in Table 3. Total group median lifetime use of 7.5 substances (including cannabis) $(\mathrm{IQR}=4)$ and past-month use of $3(\mathrm{IQR}=2)$ were recorded. The SCRA + cannabis group consumed a higher number of substances over a lifetime than the cannabis-only group $[\mathrm{Mdn}(\mathrm{IQR})=9(4) \vee 6(3), \mathrm{U}=1427 p<0.001]$ and were more likely to report lifetime use of hallucinogens $(69.5 \% \mathrm{v} 36.1 \%, p<0.001)$, synthetic stimulants $(32.9 \% \mathrm{v}$ $4.2 \%, p<0.001)$, inhalants $(26.8 \%$ v $5.6 \%, p<0.001)$, illicit opioids $(39.0 \%$ v $16.7 \%, p=0.002)$ and illicit benzodiazepines $(25.6 \%$ v $12.5 \%, p<0.04)$. The cannabis-only group were more likely to report lifetime use of prescribed opiates $(47.2 \%$ v $26.8 \%, p=0.009)$.

\section{Drug Use Motive Questionnaire (DUMQ): cannabis/SCRA}

The primary psychological motivations to consume cannabis and SCRAs were for pleasure enhancement $(\mathrm{M}=13$ and 11.3 respectively) and as a means of coping $(\mathrm{M}=12.9$ and 7.8 respectively). Both the highest scoring item of each sub-scale and the most important reasons selected to use cannabis were 'to relax' $(22 \% ; 33 / 152)$ and 'to get high' $(15 \% ; 23 / 152)$. The most frequently chosen and most important reason for SCRAs use was to get high' (46\%; 37/81), followed by 'because friends are doing it' (15\%; 12/81).

There were no differences between groups in the motives for use of cannabis. Figure 1 illustrates significant differences between the SCRA + cannabis group motives for use of cannabis and SCRAs.

\section{Effects of cannabis/SCRA use}

Table 4 describes comparison data for self-reported sideeffects experienced during or after their use of cannabis and SCRAs. Differences were reported across the spectrum including psychotic reactions and neurological and cardiovascular effects. No differences were found in the number of effects experienced between genders [M $(\mathrm{SD})=12.5(7)$ male vs 10.9(6.5) female, $p=0.36]$.

\section{Mental health}

The DASS21 scored the overall group's psychological health in the moderate range for depression and anxiety and the mild range for stress $[\mathrm{Mdn}(\mathrm{IQR})=8(8.5)$, 5(7), 8(9) respectively]. The SCRA + cannabis group indicated higher levels of stress $[\mathrm{Mdn}(\mathrm{IQR})=10(9.5)$ $\mathrm{v}$ 6.5(9), $\mathrm{U}=2270, p=0.01]$ and psychological distress overall $[\mathrm{Mdn}(\mathrm{IQR})=8(9)$ v $6(9), \mathrm{U}=23,064 p=0.01$ ] compared to the cannabis-only group. See Supplementary Materials for DASS scoring.

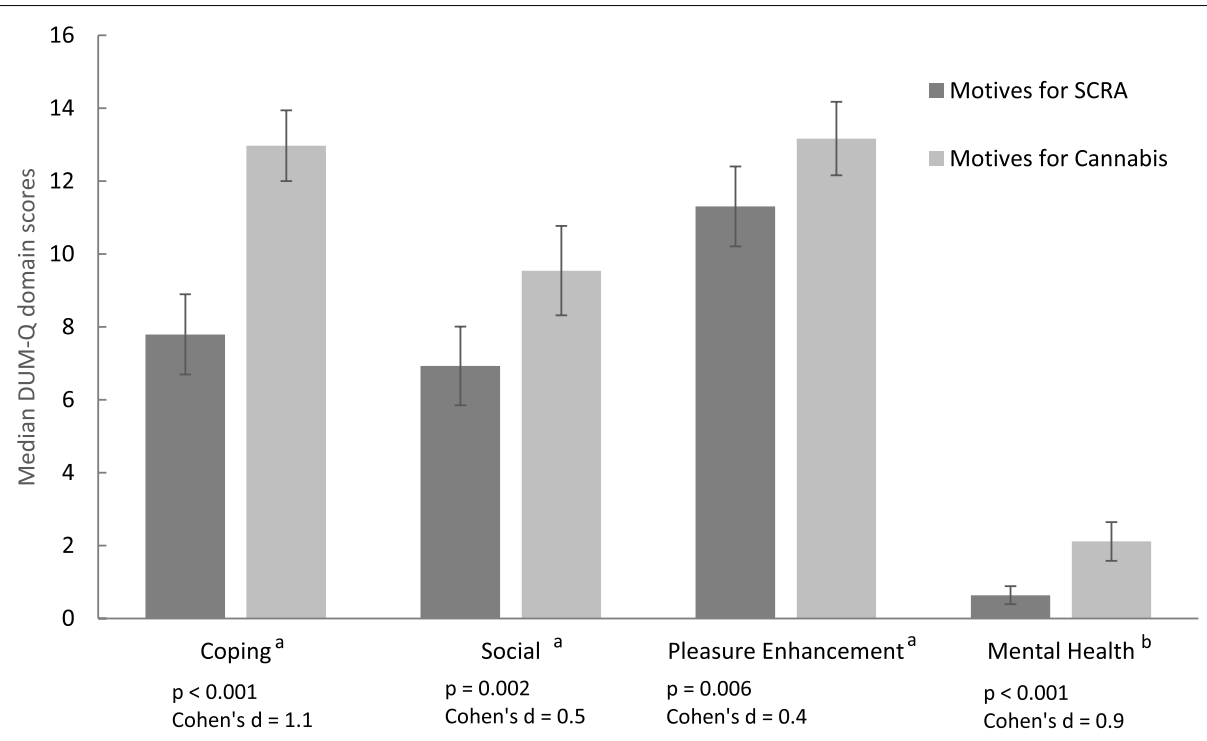

Fig. 1 Difference in median Drug Use Motives Questionnaire (DUM-Q) domain scores for SCRAs and cannabis. a The Coping, Social and Pleasure Enhancement domains consist of 4 items, each with a 5 -point response option scored 0 to 4 respectively (never $=0$, rarely $=1$, sometimes $=2$, often=3, almost always=4). $\mathbf{b}$ The Mental Health domain consists of only 2 items, each with the same response and scoring as above 
Table 4 Comparison of effects of SCRA and cannabis use as reported by 154 participants undergoing treatment for cannabis use in New South Wales, Australia

\begin{tabular}{|c|c|c|c|c|c|}
\hline Self-reported effects/experiences ${ }^{a}$ & $\begin{array}{l}\text { SCRAs } \\
(\%) \\
(n=82)\end{array}$ & $\begin{array}{l}\text { Cannabis } \\
(\%) \\
(n=72)\end{array}$ & OR & $95 \% \mathrm{Cl}$ & $\begin{array}{l}\text { McNemar Test } \\
p \text {-value }\end{array}$ \\
\hline Racing heart/irregular heartbeat & 40.2 & 9.8 & 4.1 & $1.9-8.9$ & $<0.001$ \\
\hline Nausea & 37.8 & 9.8 & 3.9 & $1.8-8.4$ & $<0.001$ \\
\hline Panic & 37.8 & 17.1 & 2.2 & $1.1-4.2$ & 0.016 \\
\hline Dizziness & 35.4 & 9.8 & 3.6 & $1.7-8.0$ & 0.001 \\
\hline Excessive Sweatiness & 31.7 & 9.8 & 3.3 & $1.5-7.2$ & 0.003 \\
\hline Hangover effect & 31.7 & 12.2 & 2.6 & $1.3-5.4$ & 0.011 \\
\hline Dream-like state & 31.7 & 22.0 & 1.4 & $0.8-2.6$ & 0.291 \\
\hline Chest pain & 28.0 & 8.5 & 3.3 & $1.4-7.7$ & 0.005 \\
\hline Hallucinations & 28.0 & 7.3 & 3.8 & $1.6-9.4$ & 0.002 \\
\hline Decreased appetite & 25.6 & 15.9 & 1.6 & $0.8-3.2$ & 0.229 \\
\hline Light headedness & 24.4 & 11.0 & 2.2 & $1.0-4.9$ & 0.061 \\
\hline Confusion/disorientation & 24.4 & 9.8 & 2.5 & $1.1-5.7$ & 0.036 \\
\hline Psychotic experiences & 20.7 & 8.5 & 2.4 & $1.0-5.9$ & 0.064 \\
\hline Headache & 20.7 & 11.0 & 1.9 & $0.8-4.2$ & 0.169 \\
\hline Paranoia & 19.5 & 13.4 & 1.5 & $0.7-3.1$ & 0.442 \\
\hline Decreased motor coordination & 19.5 & 12.2 & 1.6 & $0.7-3.5$ & 0.327 \\
\hline Decreased ability to function after use & 18.3 & 15.9 & 1.2 & $0.6-2.4$ & 0.851 \\
\hline Nervousness or anxiety & 18.3 & 12.2 & 1.5 & $0.7-3.4$ & 0.424 \\
\hline Feelings of personal isolation & 18.3 & 14.6 & 1.3 & $0.6-2.7$ & 0.701 \\
\hline Nausea or vomiting & 18.3 & 19.5 & 0.9 & $0.5-1.9$ & 1.000 \\
\hline Passed out after use of SCRAs & 17.1 & 14.6 & 1.2 & $0.5-2.5$ & 0.845 \\
\hline Felt antisocial after smoking & 17.1 & 13.4 & 1.3 & $0.6-2.8$ & 0.690 \\
\hline Slurred Speech & 17.1 & 11.0 & 1.6 & $0.7-3.6$ & 0.405 \\
\hline Ringing in the ears & 17.1 & 12.2 & 1.4 & $0.6-3.2$ & 0.541 \\
\hline Worried about meeting strangers & 15.9 & 11.0 & 1.4 & $0.6-3.4$ & 0.523 \\
\hline Depression & 13.6 & 19.8 & 0.7 & $0.3-1.5$ & 0.442 \\
\hline Convulsions & 12.2 & 4.9 & 2.5 & $0.8-8.0$ & 0.180 \\
\hline Feel more energetic & 11.0 & 34.1 & 0.3 & $0.2-0.7$ & 0.003 \\
\hline Increased ability to function after use & 8.5 & 43.9 & 0.2 & $0.1-0.4$ & $<0.001$ \\
\hline Felt sluggish/heavy & 7.3 & 18.3 & 0.4 & $0.2-1.0$ & 0.078 \\
\hline Clumsy & 6.1 & 24.4 & 0.3 & $0.1-0.7$ & 0.004 \\
\hline Drowsiness & 4.9 & 29.3 & 0.2 & $0.1-0.5$ & $<0.001$ \\
\hline Dry mouth & 2.4 & 23.2 & 1.1 & $0.0-0.5$ & $<0.001$ \\
\hline Impaired memory & 2.4 & 23.2 & 0.1 & $0.0-0.5$ & $<0.001$ \\
\hline Felt more focused than usual & 1.2 & 57.3 & 0.0 & $0.0-0.2$ & $<0.001$ \\
\hline
\end{tabular}

a Every item has four response options ( $1=$ never, 2 =sometimes, $3=$ most of the time, $4=$ every time), with each answer categorised into 'effect absent' for never responses and 'effect present' for sometimes, most of the time and always

\section{Health status}

Between-group comparisons were similar in all subscales except role physical, with the cannabis-only group indicating greater role limitations due to physical health concerns (M (SD) $=41.4(8.7)$ v 50(10.2), $p<0.001)$. Likewise, their global physical component score indicated poorer overall physical health $(\mathrm{M}(\mathrm{SD})=50.2(6.3)$ v 54.8(7.9), $p<0.001)$. Full sample data comparisons with Australian age-matched SF-36 normative data showed significantly lower functioning for both groups across all subscales except physical functioning. The global component physical score indicated no differences $(\mathrm{M}(\mathrm{SD})=52.7(7.6)$ v 52.7(7.8), $p=0.41$, but the mental component score was significantly lower when compared to population norms (M $(\mathrm{SD})=34.7(12.2) \mathrm{v} 49.4(9.6), p<0.001)$. 
Table 5 Logistic regression model predicting SCRA use in an Australian cannabis treatment population $(N=154)$

\begin{tabular}{llll}
\hline Characteristics & \multicolumn{2}{l}{ SCRA use } \\
\cline { 2 - 4 } & OR & $\mathbf{9 5 \% C l}$ & p-value \\
\hline Living arrangements_living with others & 0.3 & $0.1-0.8$ & 0.011 \\
Relationship status_in a relationship & 0.4 & $0.2-0.9$ & 0.020 \\
Cannabis dependence_ICD-10 score & 0.8 & $0.6-0.9$ & 0.012 \\
Cannabis consumer/day_grammes & 0.9 & $0.8-1.0$ & 0.083 \\
Lifetime substance use (excluding can- & 1.4 & $1.1-1.6$ & 0.001 \\
$\quad$ nabis and SCRAs) & & & \\
DASS_-stress score & 1.1 & $1.0-1.3$ & 0.180 \\
DASS_overall score & 1.0 & $0.9-1.0$ & 0.761 \\
\hline
\end{tabular}

\section{SCRA use}

\section{Predictors of SCRA use}

Results of bivariate logistic regression analysis for individual demographic, substance use and psychological wellbeing characteristics significantly associated with SCRA use are demonstrated in Table 5. These indicate that living alone, being single and having more symptoms of cannabis dependence decreased the odds of having used SCRAs, while consuming a greater number of substances increased the odds of SCRA use by $40 \%$.

\section{First, subsequent and no use}

Table 6 illustrates reasons for first and subsequent SCRA use and selection of the most influential reasons for both. It also details the cannabis-only group's reasons not to use SCRAs.

\section{Comparing SCRAs and cannabis}

Of the SCRA + cannabis group, 89\% (73/82) preferred cannabis. Most felt that it provided a safer experience (98\%; 80/82), had more positive psychoactive effects (91\%; 75/82), had longer lasting effects (79\%; 65/82), offered a more consistent product $(72 \% ; 59 / 82)$ and was better value for money $(66 \% ; 54 / 82)$. In terms of sideeffects, most participants considered SCRAs to be more harmful to the lungs than cannabis $(78 \% ; 64 / 82)$ and to have more negative psychoactive effects (91\%; 75/82). When asked which of the two they would offer a novice substance consumer, SCRA participants overwhelming elected cannabis $(93 \% ; 76 / 82)$. For those who preferred SCRAs, rationales included their superior psychoactive strength and quality, their ability to evade drug testing and ease of accessibility.

\section{Utilisation of health services}

Of the SCRA + cannabis group, 27\% (22/82) sought medical assistance in relation to SCRA use. Of these,
Table 6 Reasons for first, subsequent use and no use of SCRAs with most important reason for each highlighted and italicised

\begin{tabular}{|c|c|c|c|c|}
\hline \multirow{2}{*}{$\begin{array}{l}\text { First SCRA use }(n=82) \\
\text { Curiosity to compare effects to cannabis }\end{array}$} & \multicolumn{2}{|c|}{$\begin{array}{l}\text { Reasons for } \\
\text { SCRA use } \\
n, \%\end{array}$} & \multicolumn{2}{|c|}{$\begin{array}{l}\text { Most } \\
\text { important } \\
\text { reason } \\
n, \%\end{array}$} \\
\hline & 63 & $77 \%$ & 18 & $22 \%$ \\
\hline Offered by others/available & 51 & $62 \%$ & 15 & $18 \%$ \\
\hline Heard reports from other sources & 50 & $61 \%$ & 7 & $9 \%$ \\
\hline Offered an alternative to cannabis & 42 & $51 \%$ & 13 & $16 \%$ \\
\hline Legal status & 42 & $51 \%$ & 10 & $12 \%$ \\
\hline Easier to obtain than cannabis & 31 & $38 \%$ & 4 & $5 \%$ \\
\hline Subject to drug testing & 20 & $24 \%$ & 7 & $9 \%$ \\
\hline To reduce or cease cannabis use & 15 & $18 \%$ & 6 & $7 \%$ \\
\hline Produced desirable recreational effects & 14 & $17 \%$ & - & - \\
\hline Less expensive than cannabis & 10 & $12 \%$ & 1 & $1 \%$ \\
\hline Stronger than cannabis & 10 & $12 \%$ & 1 & $1 \%$ \\
\hline $\begin{array}{l}\text { Produced positive therapeutic/medicinal } \\
\text { effects }\end{array}$ & 7 & $9 \%$ & - & - \\
\hline Milder than cannabis & 4 & $5 \%$ & - & - \\
\hline \multicolumn{5}{|l|}{ Subsequent SCRA use $(n=72)$} \\
\hline Offered an alternative to cannabis & 37 & $51 \%$ & 7 & $10 \%$ \\
\hline Easier to obtain than cannabis & 34 & $47 \%$ & 7 & $10 \%$ \\
\hline Stronger than cannabis & 33 & $44 \%$ & 13 & $18 \%$ \\
\hline Legal status & 31 & $43 \%$ & 7 & $10 \%$ \\
\hline Offered by others/available & 31 & $43 \%$ & 9 & $13 \%$ \\
\hline Produced desirable recreational effects & 22 & $31 \%$ & 6 & $8 \%$ \\
\hline Subject to drug testing & 20 & $28 \%$ & 9 & $13 \%$ \\
\hline Curiosity to compare effects to cannabis & 19 & $26 \%$ & 9 & $13 \%$ \\
\hline $\begin{array}{l}\text { Produced positive therapeutic/medicinal } \\
\text { effects }\end{array}$ & 10 & $14 \%$ & - & - \\
\hline Less expensive than cannabis & 9 & $13 \%$ & 3 & $4 \%$ \\
\hline To reduce or cease cannabis use & 8 & $11 \%$ & 2 & $3 \%$ \\
\hline Heard reports from other sources & 8 & $11 \%$ & - & - \\
\hline Milder than cannabis & 5 & $7 \%$ & - & - \\
\hline \multicolumn{5}{|l|}{ No SCRA use $(n=72)$} \\
\hline Heard bad/negative reports & 62 & $86 \%$ & 37 & $51 \%$ \\
\hline Not a natural product & 50 & $69 \%$ & 17 & $24 \%$ \\
\hline No curiosity to try SCRAs & 40 & $56 \%$ & 5 & $7 \%$ \\
\hline Undesired recreational effects & 38 & $53 \%$ & 7 & $10 \%$ \\
\hline Distrust of SCRA manufacturers & 20 & $28 \%$ & 2 & $3 \%$ \\
\hline Never offered or available & 14 & $19 \%$ & 4 & $6 \%$ \\
\hline Negative/harmful effect profile & 14 & $19 \%$ & - & - \\
\hline Distrust of SCRA retailers & 11 & $15 \%$ & - & - \\
\hline Illegal status & 9 & $13 \%$ & - & - \\
\hline More difficult to obtain & 8 & $11 \%$ & - & - \\
\hline Stronger than cannabis & 5 & $7 \%$ & - & - \\
\hline Subject to drug testing & 3 & $4 \%$ & - & - \\
\hline More expensive & 2 & $3 \%$ & - & - \\
\hline Milder than cannabis & 2 & $3 \%$ & - & - \\
\hline
\end{tabular}


$45 \%(10 / 22)$ were admitted for hospital treatment and $32 \%(7 / 22)$ were transported by ambulance. Reasons for hospital admission included: detoxification (50\%; 5/10), psychosis $(30 \% ; 3 / 10)$, overdose $(10 \% ; 1 / 10)$ and seizures $(10 \% ; 1 / 10)$. Treatment by other medical professionals included psychologist/ counsellor (77\%; 17/22), medical practitioner (59\%; 13/22), psychiatrist $(27 \% ; 6 / 22)$ and neurologist $(14 \% ; 3 / 22)$.

\section{Discussion}

The current study examines SCRA use among treatment groups of cannabis consumers in metropolitan and regional areas of New South Wales, Australia. The cohort $(n=154)$ predominantly consisted of older [Mdn $(\mathrm{IQR})=35(18)]$, single, socioeconomically disadvantaged, cannabis-dependant males. As expected, use of multiple substances and high levels of psychological distress were recorded, with overall mental health significantly lower than that of the Australian population in the same age range.

The SCRA + cannabis group were largely male, although somewhat older $[\mathrm{Mdn}(\mathrm{IQR})=32(17)]$ than those described in earlier research (Winstock and Barratt 2013b; Barratt et al. 2013). This is consistent with recent Australian data (Grigg et al. 2020) and that from a nationwide retrospective case-series of deaths related to SCRA consumption between 2000 and 2017 (Darke et al. 2020). Here, those suffering fatal harm $(n=55)$ were male $(91 \%)$ and older age $[\mathrm{M}(\mathrm{SD})=37(12)]$ with over two-thirds having a documented history of cannabis use. Older age was associated with death due to combined toxicity and cardiovascular disease, suggesting groups such as those presenting for cannabis-related treatment may be at greatest risk of acute harm. US data on SCRA use in substance treatment populations is also consistent, with SCRA consumers being similar age $(\mathrm{M}=32.5)$ although younger than those who had not used SCRAs $(M=40.7)$. They too were predominantly single (60.3\%) with extensive substance use histories (Smith and Staton 2019).

\section{SCRA prevalence and use}

SCRA use was relatively common, with approximately half the total sample reporting lifetime use. Despite decreases in SCRA availability and use in Australia (Downey 2014), almost 20\% described previous month use and $10 \%$ reported daily use.

Our research shows that an individual's relationship with cannabis and other substances may influence SCRA use. Those less dependent on cannabis with experience using a wide range of other substances are more likely to be SCRA consumers. The SCRA + cannabis group were more socially integrated and exhibited greater poly-substance use, but were more stressed and had poorer mental health than their cannabis-only counterparts. This demonstrated use of SCRA by disadvantaged groups supports growing literature that psychosocially vulnerable communities, characterised by poly-substance use, are more likely to consume SCRAs and suffer associated harms (Manseau et al. 2017; Joseph et al. 2019; Sutherland et al. 2018). The results also align with suggestions that SCRA use is most likely in regular cannabis and amphetamine consumers (Sutherland et al. 2018).

\section{Motivations to use SCRAs}

Pleasure enhancement and coping were the most common reasons to consume SCRAs and cannabis. Curiosity was the motivation for initial SCRA use, as described in earlier studies (Bonar et al. 2014; Vandrey et al. 2012; Barratt et al. 2013). The circumvention of drug testing has previously been noted as a significant motive to use SCRAs (Bonar et al. 2014; Gunderson et al. 2014; Vandrey et al. 2012), but only one-quarter of the current SCRA + cannabis group cited this. High levels of unemployment, reducing exposure to workplace drug testing, may partly explain this difference. Reasons to continue SCRA use centred on the strength of their psychoactive effects: this response has not been highlighted in SCRA literature but does support a descriptor of NPS consumers as an innovative group of people who use substances and actively seek altered states of consciousness (Sutherland et al. 2016).

\section{Side effects}

A range of side-effects of SCRA intoxication are described, many overlapping with those seen after highdose cannabis intoxication (Fattore 2016). The present results suggest that SCRAs are more likely to induce negative side-effects (rapid heartbeat, nausea, hallucinations, chest pain, sweatiness, dizziness, and panic) than cannabis, although survey design limitations should be acknowledged. The rating scale fails to account for the relativity frequency of events and how they correspond with given response options. For example, an effect experienced three times may be rated as occurring 'sometimes' after 100 uses of cannabis, but 'nearly always' after five uses of SCRA. Consistent with other studies, only few participants reported experiencing regular postSCRA consumption psychotic symptoms and hallucinations (Barratt et al. 2013; Vandrey et al. 2012). Some effects may be difficult to attribute due to variability in the psychoactive ingredients used in SCRA products. Age, gender and concurrent use of other substances may also impact the number and severity of self-reported effects (Fattore 2016; Barratt et al. 2013). 


\section{Medical treatment}

One-quarter of the respondent's required medical treatment to address short- or long-term consequences of SCRA use. Of these, one in 20 sought emergency hospital treatment, a rate exceeding the one in 40 SCRA-related emergency medical presentations estimated by Winstock et al. (2015) (Winstock and Barratt 2013a). It is possible that the current sample, who were already experiencing problems with substance use, would be more likely to seek treatment than those who use substances and respond to internet surveys. Several other factors could also be accountable, such as age differences between survey and study respondents $[\mathrm{Mdn}(\mathrm{IQR})=23(9)$ vs $32(17)$ respectively] or time differences between data collections (2011 vs 2015 respectively), and changes in SCRA diversity in that time. The latter is consistent with recent Australian data indicating increasing probability of requiring presentation to emergency departments following SCRA consumption between 2015 and 2018 (Grigg et al. 2020) implying a pattern of escalating SCRA toxicity or more acute clinical presentation. The pharmacological literature indicates increasing SCRA potency over time, with higher numbers of recent compounds having sub nanomolar affinity at CB1 receptors (Banister S.D. and Connor M. 2018).

All hospital presentations related to serious SCRA side effects or withdrawal management rather than less serious adverse events (e.g. panic/anxiety, tachycardia or agitation) (Tait et al. 2016). Previous treatment experiences for cannabis-related problems were not explored, although exposure to SCRAs has already been shown to significantly increase the risk of short-term harms when compared to cannabis (Winstock et al. 2015; Winstock and Barratt 2013a). Comparisons with previous findings are limited by the lack of timeframes and variety of treatment services included in the current study. Nevertheless, a concerning incidence of serious harm is highlighted.

\section{Substance preferences}

In agreement with previous findings (Winstock and Barratt 2013b), an overwhelming majority of respondents preferred cannabis to SCRAs. Explanations centred on psychoactive effects (both dissatisfaction with those of SCRAs and preference for the effects of cannabis), the 'natural' verses 'synthetic' nature of the two substances and safety concerns about the use of SCRAs. The preference perhaps explains some of the decline in SCRA use seen in general populations in Australia in recent years. It is notable that despite this, SCRA use was neither uncommon nor infrequent in this group.

\section{Strengths and limitations}

This is the first Australian exploration of SCRA use in a treatment sample of people who use cannabis. Its strength lies in the face-to-face method of information collection that allowed exploration of a population that can be difficult to capture using online survey techniques. The results are broadly consistent with previous findings and provide new evidence regarding the impacts of SCRA use in substance use treatment populations.

The interview data was subject to recall bias. No toxicology screening or verification measures were undertaken, so outcomes attributed to SCRAs may be due to unrelated factors. It should also be noted that SCRAs are a broad class of substance with a wide-ranging array of SCRA product types, so consumer experiences cannot be attributed to a homogenous drug type.

The results have limited external validity given the groups specific nature and high levels of comorbid mental illness and substance use. Lastly, the relatively small sample size may limit opportunities of detecting more subtle group differences, although a range of robust findings emerged nonetheless.

\section{Conclusions}

SCRAs are one sub-category within the broad range of NPS with potential for toxicity and long-term harms to users. The study provides a picture of SCRA use in Australian cannabis treatment populations. More than half of those receiving treatment for cannabis use report lifetime SCRA use and despite changing availability, approximately one-quarter described recent SCRA use. Having a lower dependence on cannabis but higher level of other substance use may predict SCRA use. Motivations for initial SCRA consumption were curiosity but psychoactive strength precipitated continued use even though cannabis was overwhelmingly preferred by this group. Overall, SCRAs appear to induce more negative side-effects than cannabis and seeking medical assistance, including hospital admissions, was relatively common.

Those who use SCRAs are likely to experience greater poly-substance use and psychological distress than those who do not and as such these substances remain a health concern for vulnerable groups of socially disadvantaged individuals with substance use and/or mental health concerns. Future research should monitor the prevalence of even low-level SCRA and NPS use among these individuals to identify changes in availability and consumption. Clinically, the need to monitor SCRA consumption in individuals persists as identification of its use alongside other illicit drug use may indicate more severe or 
problematic patterns of substance use and/or mental health concerns requiring treatment.

\author{
Abbreviations \\ NPS: New psychoactive substances; SCRA: Synthetic cannabinoid receptor \\ agonists; NSW: New South Wales; M: Median; SD: Standard deviation; Mdn: \\ Median; IQR: Interquartile range; U: Mann-Whitney U; OR: Odds ratio; Cl: \\ Confidence interval.
}

\section{Supplementary Information}

The online version contains supplementary material available at https://doi. org/10.1186/s42238-021-00091-z.

Additional file 1. Supplementary Material.

\section{Acknowledgements}

We would like to acknowledge the participants who, in addition to their treatment, took time to participate in the Kronic in the Clinic: Impact of synthetic cannabinoids on treatment-seekers and health services study. We would also like to recognise the contributions of investigators and research staff from participating NSW Health drug and alcohol services and the support received from clinicians at NSW Health cannabis treatment clinics involved in the study. Lastly, we would like to acknowledge the important contributions made by Dave Allsop and Nghi Phung to the development and conduct of this study.

\section{Authors' contributions}

The study was conceived and designed by ADJ. Significant contributions to study design, protocol conceptualisation and development were made by $D A, J J, N L, I M, R B, N P, M M$ and RC. The study was coordinated by student MAJ under the supervision of $A D J, J B, A L B$ and $R C$. Data collection was undertaken by MAJ and JL. MJ drafted, edited and revised the manuscript with critical input from all authors, who approved the final version of the manuscript and accepted accountability for all aspects of the work (with the exception of DA and NP who are both deceased).

\section{Funding}

This work was supported by a New South Wales Health Drug and Alcohol Research Grants Program, reference number H13/115985-2.

\section{Availability of data and materials}

The data that informs the findings of this study is available from the corresponding author (MAJ) upon reasonable request.

\section{Declarations}

Ethics approval and consent to participate

Ethics approval for this study was granted by South-East Sydney Local Health District Human Research Ethics Committee, reference number 15/030 (HREC/15/POWH/56).

\section{Consent for publication}

Not applicable.

\section{Competing interests}

AJD has no conflicts of interest related to this project but reports grants from Braeburn/Camurus to conduct clinical studies with buprenorphine products and travel support to Hunter New England Local Health District, which employs AJD. He is also an investigator on an Indivior-funded study of buprenorphine products. AJD has serviced on an advisory board for Mundipharma.IM reports grants and salary support from NHMRC and grants from Lambert Initiative for Cannabinoid Therapeutics during the conduct of the study for projects unrelated to the submitted work; IM is also a consultant to Kinoxis Therapeutics and has received speaking fees from Janssen. He reports patents to WO2018107216A1, WO2017004674A1 and WO2011038451A1 issued and licensed, and patents to AU2017904438,
AU2017904072, and AU2018901971 pending.NL has no conflicts of interest related to this project but has received research funding for unrelated research with Camurus and has also served on advisory boards for Indivior, Mundipharma and Camurus.All other authors have no competing interests to declare and have no support from any organisation or other relationships or activities that could appear to have influenced the submitted work.

\section{Author details}

${ }^{1}$ Drug and Alcohol Clinical Services, Hunter New England Local Health District, Level 3, 670 Hunter Street, Newcastle, NSW 2290, Australia. ${ }^{2}$ University Centre for Rural Health, University of Sydney, Lismore, NSW, Australia. ${ }^{3}$ Centre for Brain and Mental Health Research, Hunter New England Local Health District, Newcastle, NSW, Australia. ${ }^{4}$ The Lambert Initiative for Cannabinoid Therapeutics, Brain and Mind Centre, University of Sydney, Sydney, NSW, Australia. ${ }^{5}$ School of Health, University of Tasmania, Hobart, TAS, Australia. ${ }^{6}$ Drug and Alcohol Services, South East Sydney Local Health District, Sydney, NSW, Australia. ${ }^{7}$ Drug and Alcohol Services, Northern Sydney Local Health District, Sydney, NSW, Australia. ${ }^{8}$ Drug Health, Western Sydney Local Health District, Sydney, NSW, Australia. ${ }^{9}$ Faculty of Science and Information Technology, University of Newcastle, Newcastle, NSW, Australia. ${ }^{10}$ Drug Health, Western Sydney Local Health District, Parramatta, NSW, Australia.

Received: 14 October 2020 Accepted: 9 July 2021

Published online: 26 July 2021

\section{References}

Banister SD, Connor M. The chemistry and pharmacology of synthetic cannabinoid receptor agonist new psychoactive substances: evolution. In: Maurer H, Brandt S, editors. New Psychoactive Substances, vol Handbook of Experimental Pharmacology, vol. 252. Cham: Springer; 2018. p. 191-226.

Barratt MJ, Cakic V, Lenton S. Patterns of synthetic cannabinoid use in Australia. Drug Alcohol Rev. 2013;32(2):141-6. https://doi.org/10.1111/j.1465-3362. 2012.00519.x

Blackman S, Bradley R. From niche to stigma—headshops to prison: exploring the rise and fall of synthetic cannabinoid use among young adults. Int J Drug Policy. 2017;40:70-7. https://doi.org/10.1016/j.drugpo.2016.10.015.

Bonar EE, Ashrafioun L, Ilgen MA. Synthetic cannabinoid use among patients in residential substance use disorder treatment: prevalence, motives, and correlates. Drug Alcohol Depend. 2014;143:268-71. https://doi.org/10. 1016/j.drugalcdep.2014.07.009.

Cairns R, Brown JA, Gunja N, Buckley NA. The impact of Australian legislative changes on synthetic cannabinoid exposures reported to the New South Wales Poisons Information Centre. Int J Drug Policy. 2017:43:74-82. https://doi.org/10.1016/j.drugpo.2017.02.008.

Clancy RV, Hodgson RC, Kendurkar A, Terry MA, Dadd L, Clancy DM, Ryan K, Hatzistylis M, Tinman BG. Synthetic cannabinoid use in an acute psychiatric inpatient unit. Int J Ment Health Nurs. 2018;27(2):600-7. https://doi. org/10.1111/inm.12341

Cooper ML, Russell M, Skinner JB, Windle M. Development and validation of a three-dimensional measure of drinking motives. Psychol Assess. 1992;4(2):123-32. https://doi.org/10.1037/1040-3590.4.2.123.

Darke S, Duflou J, Farrell M, Peacock A, Lappin J. Characteristics and circumstances of synthetic cannabinoid-related death. Clin Toxicol. 2020;58(5):368-74. https://doi.org/10.1080/15563650.2019.1647344

Downey M. Use of synthetic cannabinoids drops. National Drug \& Alcohol Research Centre, University of New South Wales [Internet]. 2014 Oct 20 [cited 2021 Jan 20]. Available from: https://ndarc.med.unsw.edu.au/news/ use-synthetic-cannabis-drops.

European Monitoring Centre for Drugs and Drug Addiction. High-risk drug use and new psychoactive substances. Luxembourg: Publications Office of the European Union; 2017. https://doi.org/10.2810/807363.

European Monitoring Centre for Drugs and Drug Addiction. Fentanils and synthetic cannabinoids: driving greater complexity into the drug situation. An update from the EU Early Warning System. Luxembourg: Publications Office of the European Union; 2018. https://doi.org/10.2810/603753.

European Monitoring Centre for Drugs and Drug Addiction and Europol. EU Drug Markets Report 2019. Luxembourg: Publications Office of the European Union; 2019. https://doi.org/10.2810/796253. 
Fantegrossi WE, Moran JH, Radominska-Pandya A, Prather PL. Distinct pharmacology and metabolism of K2 synthetic cannabinoids compared to Delta(9)-THC: mechanism underlying greater toxicity? Life Sci. 2014;97(1):45-54. https://doi.org/10.1016/j.lfs.2013.09.017.

Fattore L. Synthetic cannabinoids - further evidence supporting the relationship between cannabinoids and psychosis. Biol Psychiatry. 2016;79(7):539-48. https://doi.org/10.1016/j.biopsych.2016.02.001.

Fattore L, Fratta W. Beyond THC: the new generation of cannabinoid designer drugs. Front Behav Neurosci. 2011;5:60. https://doi.org/10.3389/fnbeh 2011.00060

Grigg J, Killian JJ, Matthews S, Scott D, Arunogiri S, Manning V, Taylor DA, Cros$\sin$ R, Smith K, Lubman DI. The impact of legislation on acute synthetic cannabinoid harms resulting in ambulance attendance. Int J Drug Policy. 2020;79:102720. https://doi.org/10.1016/j.drugpo.2020.102720.

Gunderson EW, Haughey HM, Ait-Daoud N, Joshi AS, Hart CL. A survey of synthetic cannabinoid consumption by current cannabis users. Subst Abus. 2014;35(2):184-9. https://doi.org/10.1080/08897077.2013.846288.

Joseph A, Lekas H-M, Manseau M, Lewis C. A polydrug and psychosocial profile of synthetic cannabinoid use in a New York City community sample, 2016-2017. Subst Use Misuse. 2019;54(2):282-7. https://doi.org/10.1080/ 10826084.2018 .1517178$.

Lovibond SH, Lovibond PF. Manual for the depression anxiety stress scales. 2nd ed. Sydney: Psychology Foundation of Australia; 1995.

Macgregor S, Payne J. Synthetic Cannabis: Prevalence of use among offenders, perception of risk and negative side effects experienced. NCPIC Criminal Justice Bulletin. Australian Institute of Criminology; 2013. 10 p. Series 11.

Manseau MW, Rajparia A, Joseph A, Azarchi S, Goff D, Satodiya R, Lewis CF. Clinical characteristics of synthetic cannabinoid use in a large urban psychiatric emergency setting. Subst Use Misuse. 2017;52(6):822-5. https:// doi.org/10.1080/10826084.2016.1263663.

Peacock A, Bruno R, Gisev N, Degenhardt L, Hall W, Sedefov R, White J, Thomas $\mathrm{KV}$, Farrell M, Griffiths P. New psychoactive substances: challenges for drug surveillance, control, and public health responses. Lancet. 2019;394(10209):1668-84. https://doi.org/10.1016/S0140-6736(19) 32231-7.

Potts AJ, Cano C, Thomas SHL, Hill SL. Synthetic cannabinoid receptor agonists: classification and nomenclature. Clin Toxicol (phila). 2020;58(2):82-98. https://doi.org/10.1080/15563650.2019.1661425.

Ralphs R, Williams L, Askew R, Norton A. Adding spice to the porridge: the development of a synthetic cannabinoid market in an English prison. Int J Drug Policy. 2017;40:57-69. https://doi.org/10.1016/j.drugpo.2016.10. 003.

Seely KA, Brents LK, Radominska-Pandya A, Endres GW, Keyes GS, Moran JH, Prather PL. A major glucuronidated metabolite of JWH-018 is a neutral antagonist at CB1 receptors. Chem Res Toxicol. 2012;25(4):825-7. https:// doi.org/10.1021/t×3000472.

Smith KE, Bunting AM, Staton M, Walker R, Shalash S, Winston E, Pangburn K. Examination of synthetic cannabinoid and cathinone use among a drugusing offender sample, 2013-2015. J Psychoactive Drugs. 2017:49(5):43645. https://doi.org/10.1080/02791072.2017.1361560.

Smith KE, Staton M. Synthetic cannabinoid use among a sample of individuals enrolled in community-based recovery programs: are synthetic cannabinoids actually preferred to other drugs? Subst Abus. 2019;40(2):160-9. https://doi.org/10.1080/08897077.2018.1528495.

Spaderna M, Addy PH, D'Souza DC. Spicing things up: synthetic cannabinoids. Psychopharmacology (Berl). 2013;228(4):525-40. https://doi.org/10.1007/ s00213-013-3188-4

Sutherland R, Peacock A, Roxburgh A, Barratt MJ, Burns L, Bruno R. Typology of new psychoactive substance use among the general Australian population. Drug Alcohol Depend. 2018;188:126-34. https://doi.org/10.1016/j. drugalcdep.2018.03.034.

Sutherland R, Peacock A, Whittaker E, Roxburgh A, Lenton S, Matthews A, Butler K, Nelson M, Burns L, Bruno R. New psychoactive substance use among regular psychostimulant users in Australia, 2010-2015. Drug Alcohol Depend. 2016;161:110-8. https://doi.org/10.1016/j.drugalcdep. 2016.01.024.

Swift W, Wong A, Li KM, Arnold JC, McGregor IS. Analysis of cannabis seizures in NSW, Australia: cannabis potency and cannabinoid profile. PLoS ONE. 2013;8(7): e70052. https://doi.org/10.1371/journal.pone.0070052.

Tait RJ, Caldicott D, Mountain D, Hill SL, Lenton S. A systematic review of adverse events arising from the use of synthetic cannabinoids and their associated treatment. Clin Toxicol (phila). 2016;54(1):1-13. https://doi.org/ 10.3109/15563650.2015.1110590.

van Amsterdam J, Brunt T, van den Brink W. The adverse health effects of synthetic cannabinoids with emphasis on psychosis-like effects. J Psychopharmacol. 2015;29(3):254-63. https://doi.org/10.1177/0269881114 565142.

Vandrey R, Dunn KE, Fry JA, Girling ER. A survey study to characterize use of Spice products (synthetic cannabinoids). Drug Alcohol Depend. 2012;120(1-3):238-41. https://doi.org/10.1016/j.drugalcdep.2011.07.011.

Ware JE, Kosinski M, Dewey JE. How to score Version 2 of the SF-36 Health Survey (Standard and Acute forms). 3rd ed. Lincoln: Quality Metric; 2002.

Winstock A, Lynskey M, Borschmann R, Waldron J. Risk of emergency medical treatment following consumption of cannabis or synthetic cannabinoids in a large global sample. J Psychopharmacol. 2015;29(6):698-703. https:// doi.org/10.1177/0269881115574493.

Winstock AR, Barratt MJ. The 12-month prevalence and nature of adverse experiences resulting in emergency medical presentations associated with the use of synthetic cannabinoid products. Hum. 2013;28(4):390-3. https://doi.org/10.1002/hup.2292.

Winstock AR, Barratt MJ. Synthetic cannabis: a comparison of patterns of use and effect profile with natural cannabis in a large global sample. Drug Alcohol Depend. 2013;131(1-2):106-11. https://doi.org/10.1016/j.druga Icdep.2012.12.011.

World Health Organization. The ICD-10 classification of mental and behavioural disorders: clinical descriptions and diagnostic guidelines. Geneva: World Health Organisation; 1992.

\section{Publisher's Note}

Springer Nature remains neutral with regard to jurisdictional claims in published maps and institutional affiliations.
Ready to submit your research? Choose BMC and benefit from:

- fast, convenient online submission

- thorough peer review by experienced researchers in your field

- rapid publication on acceptance

- support for research data, including large and complex data types

- gold Open Access which fosters wider collaboration and increased citations

- maximum visibility for your research: over 100M website views per year

At BMC, research is always in progress.

Learn more biomedcentral.com/submissions 